\title{
A OCUPAÇÃO COMO PROCESSO DE DESCOLONIZAÇÃO DA ESCOLA: NOTAS SOBRE UMA PESQUISA ETNOGRÁFICA
}

\author{
OCCUPATION AS A SCHOOL DECOLONIZATION PROCESS: \\ NOTES ON AN ETHNOGRAPHIC RESEARCH
}

\section{OCUPACIÓN COMO PROCESO DESCOLONIZACIÓN DE LA ESCUELA: NOTAS EN UNA BÚSQUEDA ETNOGRÁFICA}

\begin{abstract}
Luciano Nascimento Corsino
Dirce Djanira Pacheco e Zan ${ }^{2}$

\section{RESUMO}

O ano de 2015 foi marcado pelo fenômeno das ocupações de uma média de 213 escolas da rede estadual de São Paulo. O presente trabalho faz parte de pesquisa de doutorado em andamento e tem como objetivo central apresentar uma reflexão acerca da experiência de um pesquisador em ocupação realizada por jovens estudantes em uma escola da rede estadual de São Paulo. Por meio de pesquisa etnográfica, somaram-se 15 horas de observação e registros em diário de campo no interior da ocupação de uma escola localizada na zona norte de São Paulo. Dentre os fatos observados, destacam-se a forte autonomia dos/as jovens ocupantes, o ambiente democrático construído nas relações cotidianas e nos eventos promovidos, como as aulas abertas e as oficinas, assim como a tensão constante nas relações estabelecidas com os sujeitos contrários à ocupação. Verificou-se que a experiência da ocupação contribuiu efetivamente para a reflexão dos/as estudantes sobre a construção de uma escola democrática.
\end{abstract}

PALAVRAS-CHAVE: Juventude. Democracia. Participação política. Etnografia.

\section{ABSTRACT}

The year 2015 was marked by the phenomenon of occupations of 213 state public schools of São Paulo. The present work composes a doctoral research and its main objective is to present a reflection on the experience of a researcher in an occupation carried out by young students in a public state school of São Paulo. Through an ethnographic research, we added 15 hours of observation and records in field diaries within the occupation of a school located in the north area of São Paulo. Among the observed facts, the strong autonomy of the young occupants, the democratic environment built in everyday relationships and promoted events, such as open classes and workshops, as well as the constant tension in the relationships established with the subjects opposed to the occupation. It was verified that the experience of the occupation contributed effectively to the reflection of the students on the construction of a democratic school.

KEYWORDS: Youth. Decolonization. Political participation. School ethnography.

\footnotetext{
${ }^{1}$ Doutorando em Educação - Universidade Estadual de Campinas (UNICAMP). Mestre em Educação e Saúde na Infância e na Adolescência - Escola de Filosofia, Letras e Ciências Humanas - Universidade Federal de São Paulo (UNIFESP). Pesquisador do Grupo de Estudos e Pesquisas Educação, Comunicação e Feminismos Universidade Federal de Juiz de Fora (UFJF) - Juiz de Fora, MG. Email: luciano.corsino@hotmail.com ORCID: http://orcid.org/0000-0002-2591-5472

${ }^{2}$ Doutora em Educação - Universidade Estadual de Campinas (UNICAMP). Professora e Diretora da Faculdade de Educação da Universidade Estadual de Campinas (UNICAMP) - Campinas, SP. Email: dircezan@unicamp.br Submetido em: 30/11/2016 - Aceito em: 11/02/2017
}

(C) ETD-Educação Temática Digital Campinas, SP v.19 $\quad$ n.1 $\quad$ p. 26-48 jan./mar. 2017 
RESUMEN

El año 2015 estuvo marcado por el fenómeno de las ocupaciones de 213 escuelas públicas del estado de São Paulo. Este trabajo constituye una investigación de doctorado y tuvo como objetivo presentar una reflexión de experimentar un investigador en una ocupación por jóvenes estudiantes en una escuela del estado de São Paulo. A través de la investigación etnográfica, se añadieron a 15 horas de observación y registros en el diario de campo dentro de la ocupación de una escuela ubicada en el norte de São Paulo. Entre los hechos observados, destaca la fuerte autonomía de las personas jóvenes, su entorno construido democrático en las relaciones cotidianas y promovidos eventos, tales como clases y talleres abiertos, así como una tensión constante en las relaciones establecidas con los sujetos en contra de la ocupación. Se encontró que la experiencia de la ocupación contribuyó eficazmente a la reflexión de los/las estudiantes sobre la construcción de una escuela democrática.

PALABRAS CLAVE: Juventud. Descolonización. Participación política. Etnografía escolar.

\section{INTRODUÇÃO}

O ano de 2015 foi marcado pelo fenômeno das ocupações de cerca de $213^{3}$ escolas da rede estadual de São Paulo. No dia 26 de outubro, a Secretaria de Educação do Estado de São Paulo (SEE-SP) anunciou que 94 escolas da rede seriam fechadas e os/as estudantes seriam transferidos/as para escolas no entorno. O plano seria parte de um programa que ficou conhecido como "reorganização" escolar, anunciado pelo governo no dia 23 setembro do mesmo ano. Segundo Januário et al. (2016) e Campos et al. (2016), a SEE-SP utilizou dois argumentos centrais para justificar a necessidade da reorganização: a possível diminuição do número de matrículas e um estudo ${ }^{4}$ responsável por indicar que os/as alunos/as de escolas de ciclo único teriam uma melhora de $10 \%$ em seu desempenho.

Rapidamente, instituições como o Sindicato dos Professores do Ensino Oficial do Estado de São Paulo (APEOESP) e diversas universidades públicas ${ }^{5}$ se posicionaram contra o plano de reorganização, questionando desde a ausência de diálogo com as instâncias e os sujeitos afetados diretamente, até a falta de critérios científicos para sua execução (JANUÁRIO et al., 2016; CAMPOS et al., 2016). Ao mesmo tempo, os/as estudantes também

\footnotetext{
${ }^{3}$ Segundo Januário (et al., 2015), não há um número exato do total de escolas ocupadas, enquanto a SEE-SP diverge para baixo, dados coletados na internet divergem para cima. No entanto, os/as autores/as afirmam que 213 é o número mais fiel possível, apesar de considerarem que há possibilidade de este número ter sido maior.

${ }^{4} \mathrm{O}$ estudo foi conduzido pela Coordenadoria de Informação, Monitoramento e Avaliação Educacional (JANUÁRIO et al., 2016; CAMPOS et al., 2016).

${ }^{5}$ Importante registrar o estudo divulgado por um grupo de professores da Universidade Federal do ABC (SP) intitulado: Análise da política pública de Reorganização Escolar proposta pelo governo do Estado de São Paulo, divulgado em novembro de 2015. Disponível em: <https://avaliacaoeducacional.files.wordpress.com/2015/12/reorganizac3a7c3a3o-spanc3a1lise-da-ufabc.pdf>. Acesso em: 22 fev. 2017.
}

(C) ETD-Educação Temática Digital Campinas, SP $\quad$ v.19 $\quad$ n.1 $\quad$ p. 26-48 jan./mar. 2017 
organizaram sua resposta. No dia 10 de novembro, a primeira escola da rede foi ocupada. Em seguida, o número de escolas ocupadas passou a crescer. Estima-se que mais de duzentas escolas foram ocupadas em toda a rede estadual.

Nesse mesmo período, em razão do desenvolvimento da pesquisa de campo do projeto de doutorado intitulado "Cotidiano escolar e juventude negra: uma abordagem etnográfica em escola de ensino médio" ${ }^{6}$, o cotidiano em duas escolas estaduais na cidade de São Paulo era acompanhado. Com o objetivo de analisar as interseccionalidades entre gênero, raça e juventude no Ensino Médio, me inseri no cotidiano dessas duas escolas. A pesquisa estava em fase final de coleta de dados, entrevistas e observações quando ocorreu a ocupação de uma das escolas, na investigação intitulada Escola 2. Durante os dias em que os/as estudantes permaneceram no interior da escola, o movimento da ocupação foi o nosso principal foco e, diante das incertezas sobre o futuro daquela escola e daqueles/as estudantes, passamos a ter como objetivo acompanhar como seria este processo até o seu desfecho.

Por meio de pesquisa etnográfica, somaram-se observações, registros em diário de campo, conversas informais e fotografias do cotidiano da ocupação na Escola 2. Dentre os fatos observados, destacam-se a forte autonomia dos/as jovens ocupantes e suas reivindicações no sentido da construção de uma escola aberta ao diálogo; o ambiente democrático construído nas relações cotidianas entre eles/as e nos eventos promovidos, como as aulas abertas e as oficinas, assim como a tensão constante nas relações estabelecidas com os sujeitos contrários à ocupação. Verificou-se que a experiência da ocupação contribuiu efetivamente para a reflexão dos/as estudantes sobre a necessidade de construir uma escola democrática.

\section{A OCUPAÇÃO: UM ACONTECIMENTO EM MEIO À PESQUISA ETNOGRÁFICA}

Desde fevereiro de 2015, o cotidiano da Escola 2 era acompanhado semanalmente. Durante esse período, eu buscava compreender como os/as jovens, segundo sua condição de raça e gênero, se relacionavam com a escola. Entretanto, no dia oito de dezembro daquele ano, ao chegar à escola para entrevistar uma professora conforme combinado anteriormente, foi possível perceber, ainda do lado de fora, que havia um grupo de

\footnotetext{
${ }^{6}$ Trata-se do projeto "Cotidiano escolar e juventude negra: uma abordagem etnográfica em escola de ensino médio", financiado pela Coordenação de Aperfeiçoamento de Pessoal de Nível Superior (CAPES), em andamento no âmbito do Programa de Pós-Graduação da Faculdade de Educação da Unicamp.
}

(C) ETD-Educação Temática Digital Campinas, SP v.19 $\quad$ n.1 $\quad$ p. 26-48 jan./mar. 2017 
professores/as e vários carros para fora do estacionamento. Tratava-se de uma movimentação totalmente diferente da rotina com a qual estava acostumado, que era chegar à escola e encontrar um cenário tranquilo no lado externo.

Ainda sem saber o que estava ocorrendo e ao observar a movimentação diferente, peguei o celular para fazer fotografias e assim dar continuidade à pesquisa etnográfica. Nesse momento, a ação se deu em consonância com o que Ludke e André (1986) apontam em seu artigo sobre etnografia escolar, ou seja, é preciso considerar que em estudos etnográficos as circunstâncias e os caminhos escolhidos acabem se modificando e, culminando, algumas vezes, na mudança de hipóteses e até do objeto definido inicialmente. Nesse sentido, o foco estava voltado às incertezas do campo de pesquisa, àquilo que deveria ser descoberto naquele instante.

Deslocando-me ao redor da escola, encontrei um carro de polícia parado em frente ao portão de entrada, a uns 100 metros de onde estava a movimentação, no portão do estacionamento dos/as funcionários/as.

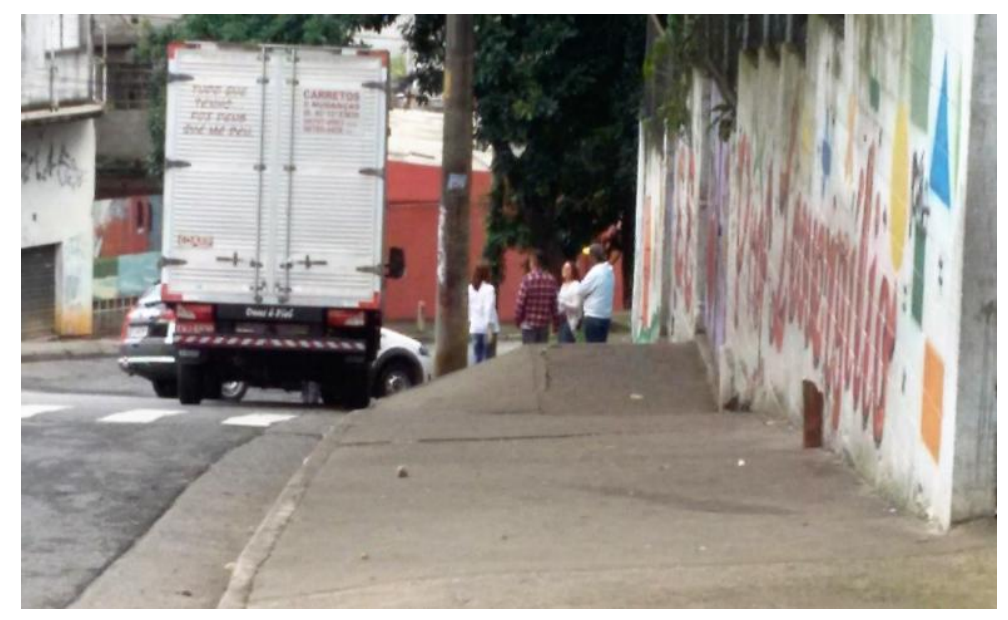

FIGURA 1 - Carro de polícia parado em frente ao portão de entrada da escola Fonte: Diário de campo

Deixando o carro na rua, não muito próximo à entrada da escola, caminhei até o local onde os/as professores/as estavam e fui recebido pela coordenadora que ao ver que eu estava com o celular em mãos disse: "não pode filmar, nem tirar foto". Foi então que perguntei o motivo: "por quê?" Ao que ela respondeu: "Porque a escola foi invadida". Me

(C) ETD-Educação Temática Digital Campinas, SP v.19 $\quad$ n.1 $\quad$ p. 26-48 jan./mar. 2017 
dirigi até o portão do estacionamento para verificar o que acontecia e me deparei com cerca de 15 professores/as inconformados/as, numa postura clara de oposição ao movimento, discutindo com alguns/mas jovens que por vezes apareciam no portão, do lado de dentro da escola.

A coordenadora estava transtornada, dizendo aos/às professores/as para olharem os carros "estranhos", não deixarem qualquer pessoa filmar ou fotografar e tomarem cuidado com o carro da APEOESP; ela se mostrava sem saber como lidar com a situação. Também estavam presentes a vice-diretora, o coordenador e a diretora da escola. Ao mesmo tempo em que ocorria aquela movimentação, eu procurava observar o máximo de reações e diálogos, tentando registrar a situação de conflitos que se colocava, considerando que as observações são aquelas em que se investigam aspectos específicos em determinados eventos, de acordo com o problema de pesquisa (VIANNA, 2003).

Para Tura (2003, p. 184), no momento da observação, o pesquisador "estabelece uma relação de conhecimento com seu objeto de estudo, que é, por sua vez, um fenômeno concreto da vida social, imbricado em relações sociais e de poder e numa rede de significados socialmente compartilhados". No mesmo sentido, Oliveira (2013) aponta que, em uma pesquisa etnográfica, há um desafio que está colocado nos processos interpretativos, segundo os quais devem ser consideradas variáveis como as diferentes condições dos/as investigados/as.

O processo interpretativo, na investigação educacional, apresenta-se como um desafio não só metodológico, mas também institucional, considerando o que está em jogo. As posições que os sujeitos ocupam, neste campo, remetem a estruturas demarcadas, hierarquizadas e verticalizadas. A dificuldade de estabelecer um diálogo, assentado na assimetria que se constitui entre pesquisador e pesquisado, explicita-se exponencialmente quando tratamos de uma pesquisa que se desenvolve num ambiente institucional, no caso, a escola (OLIVEIRA, 2013, p. 276).

Com o passar do tempo, foi possível perceber que algumas professoras estavam no interior da escola junto aos/às estudantes. Eram as duas professoras de Filosofia, a de Sociologia e outra que não foi identificada naquele momento, mas depois se descobriu ser a professora de Artes. Pelo lado de dentro da escola, no portão do estacionamento, uma das professoras disse, em tom de ironia, que lá dentro também estavam uma pastora e um padre; depois foi possível descobrir que ela se referia a um professor de História e a uma professora de Filosofia.

(C) ETD-Educação Temática Digital Campinas, SP v.19 $\quad$ n.1 $\quad$ p. 26-48 jan./mar. 2017 
Os/as professores/as e a direção chamaram o Conselho Tutelar, que, por sua vez, chamou a polícia. A conselheira chegou e pediu para entrar, dizendo que ela queria ajudar os/as jovens da ocupação. Então um dos jovens disse que ela entraria sim, mas que deveria esperar a chegada da advogada que os/as acompanharia. Após meia hora de espera, um jovem abriu o portão e elas entraram, logo a polícia chegou e, em seguida, uma advogada de defesa dos/as estudantes. Antes da chegada da advogada, algumas pessoas, dentre professores/as, responsáveis e funcionários/as, estavam extremamente exaltados/as, o que provocou alguns momentos de discussão e até de agressões com empurrões entre eles/as.

Alguns diziam que havia droga e bebida do lado de dentro da escola, sem sequer ter tido acesso a esse espaço. De certo modo, essa desconfiança aponta para uma postura que tende a criminalizar os jovens e, em especial, os jovens moradores das periferias. A juventude é vista historicamente como um grupo social que tende à transgressão e à violência, imagem que é reforçada especialmente pela grande mídia. Imagens de jovens associada à aventura, às posturas contestatória e irresponsável, são recorrentemente veiculadas por noticiários e pela publicidade. Como nos alerta KELLNER (1995), a televisão pode ser interpretada como a máquina de imagens mais prolífica da história, imagens que não apenas vendem produtos, mas também visão de mundo.

Muitos estavam pedindo para familiares ali presentes que chamassem outras famílias e quebrassem os cadeados para retirar os/as jovens à força. Nessa proposta de ação, fica evidente a tendência autoritária no trato com os jovens estudantes. O diálogo é facilmente substituído em momentos de confrontos, pelo uso da força e da imposição da autoridade do adulto, mesmo em ambientes que deveriam atuar no sentido da formação autônoma desses sujeitos, como é o caso da escola. Nesse contexto, apareceu um martelo e uma chave de fenda e um pai tentou quebrar o cadeado do portão, mas uma professora não deixou, dizendo que esse ato poderia trazer problemas para os/as professores/as.

Durante um tempo considerável, no interior da escola, ficaram conversando: diretora, conselheira e advogada. Após saírem, a diretora conversou com algumas professoras, dizendo que os/as jovens liberariam a sua entrada e a da secretária para que pudessem encaminhar algumas pendências da administração, fazer as matrículas e outras atividades, desde que fossem acompanhadas por algum/a dos/as jovens ocupantes; a secretária não aceitou: "imagina ser escoltada por um menino de quinze anos". Logo em seguida, outra professora complementou: "analfabeto ainda". A situação relatada remete às relações de poder hierarquizadas, costumeiramente estabelecidas no interior da escola,

(C) ETD-Educação Temática Digital Campinas, SP $\quad$ v.19 $\quad$ n.1 $\quad$ p. 26-48 jan./mar. 2017 
onde os/as jovens, pobres, negros/as, homossexuais e analfabetos/as, muitas vezes, são vistos em um papel de submissão (VALVERDE e STOCCO, 2011). De certo modo, sinaliza também uma relação hostil e desrespeitosa para com os/as jovens, os quais, por muitas vezes, como no caso dessa escola, são desconsiderados como sujeitos sociais, com posicionamentos, ideias e opiniões sobre a instituição e o cotidiano escolar.

Uma das professoras (que tinha cabelo crespo e volumoso cacheado) foi até o estacionamento com alguns/mas dos/as jovens/as que ocuparam a escola e, ao ver a cena, outra professora, esta loira de cabelos lisos, que estava ao meu lado protestando contra a ocupação, gritou: "olha o cabelo dessa daí", num claro tom racista. Essa manifestação remete aos estudos de pesquisadoras como hooks ${ }^{7}$ (2005) e Gomes (2002; 2003) que produziram diversas pesquisas sobre as construções culturais do corpo, tendo o cabelo como objeto de análise sobre as hierarquizações raciais. Para as autoras, o cabelo tem sido uma das formas mais cruéis na demarcação das identidades raciais. Na escola, por exemplo, a partir de observações, é possível afirmar que meninas de cabelo crespo têm sofrido racismo cotidianamente.

Depois da confusão, iniciei a busca por uma forma de aproximação com o grupo responsável pela ocupação. Almejava, assim, me aproximar e me inserir naquele espaço para dar continuidade ao trabalho investigativo. Após conversar com a professora de Artes, que estava do lado de dentro do portão, me apresentei, falei sobre a pesquisa e afirmei meu posicionamento favorável à ocupação. Foi então que a professora disse que eles/as tinham programação de oficinas e palestras abertas ao público, sendo que uma delas seria uma palestra sobre movimento negro no Brasil e nos Estados Unidos. Surgiu daí, então, a oportunidade de acompanhar as atividades no interior da ocupação.

\section{A OCUPAÇÃO COMO PROCESSO DE DESCOLONIZAÇÃO DO CURRÍCULO}

A notícia de que haveria uma palestra aberta ao público na escola foi central para a minha inserção na ocupação. Ao chegar na Escola 2, em 10 de dezembro de 2016, dia da primeira palestra, havia uma mãe do lado de fora. De repente, apareceu um menino, que a

\footnotetext{
${ }^{7}$ Os trabalhos de bell hooks são citados em caixa baixa por força de solicitação da própria autora, seu nome é Gloria Jean Watkins e bell hooks é um pseudônimo construído por ela mesma em homenagem à sua avó.
}

(C) ETD-Educação Temática Digital Campinas, SP v.19 $\quad$ n.1 $\quad$ p. 26-48 jan./mar. 2017 
atendeu e a orientou sobre a rematrícula, dizendo que ela deveria aguardar até o fim da ocupação.

Dirigindo-se para o garoto, eu disse que estava ali para assistir a palestra. 0 estudante então abriu o portão e me convidou para entrar. No interior da ocupação, estavam todos/as à espera da palestra cujo tema era "Pós-colonialismo". Essa foi uma atividade realizada por uma professora de Filosofia, que não conhecia a escola e ficou sabendo da ocupação por meio de amigos/as.

Todos/as estavam muito desconfiados/as, vários/as jovens me perguntaram quem eu era e o que estava fazendo ali na ocupação. Minha resposta sempre foi informativa, falando da pesquisa e dizendo que estava interessado em acompanhar a ocupação, como pesquisador e como um apoiador do movimento. Neste primeiro momento, minha opção foi por não fazer anotações ali na escola, mas deixar para fazê-las posteriormente, por meio da rememoração dos fatos, pois o clima era de muita desconfiança, medo e incertezas.

Nesta primeira entrada à ocupação, não pude acessar todos os lugares que estavam sendo utilizados pelos/as jovens. Fui autorizado apenas a acessar o pátio, onde seria realizada a palestra, e a sala da biblioteca, onde eles/as faziam reuniões. Percebi que na roda de conversa construída para a palestra, havia estudantes e ex-estudantes da escola, bem como professoras e ex-professoras daquela instituição, interessadas em construir um ambiente de diálogo capaz de tecer caminhos para reflexões mais aprofundadas sobre a dimensão do que estava ocorrendo naquele momento de ocupação de diversas escolas da rede estadual de ensino.

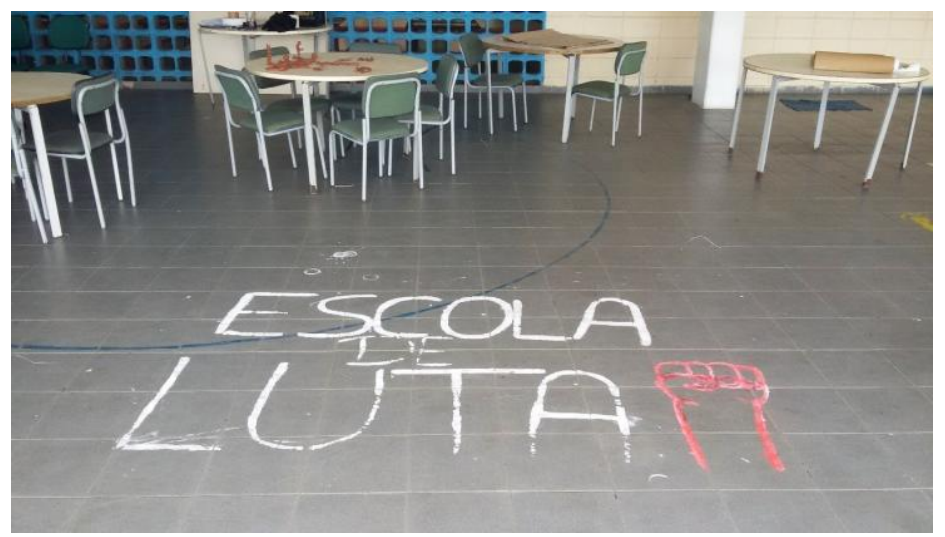

FIGURA 2 - Pátio onde foi realizada a palestra sobre Pós-colonialismo

(C) ETD-Educação Temática Digital Campinas, SP $\quad$ v.19 $\quad$ n.1 $\quad$ p. 26-48 jan./mar. 2017 
Fonte: Diário de campo

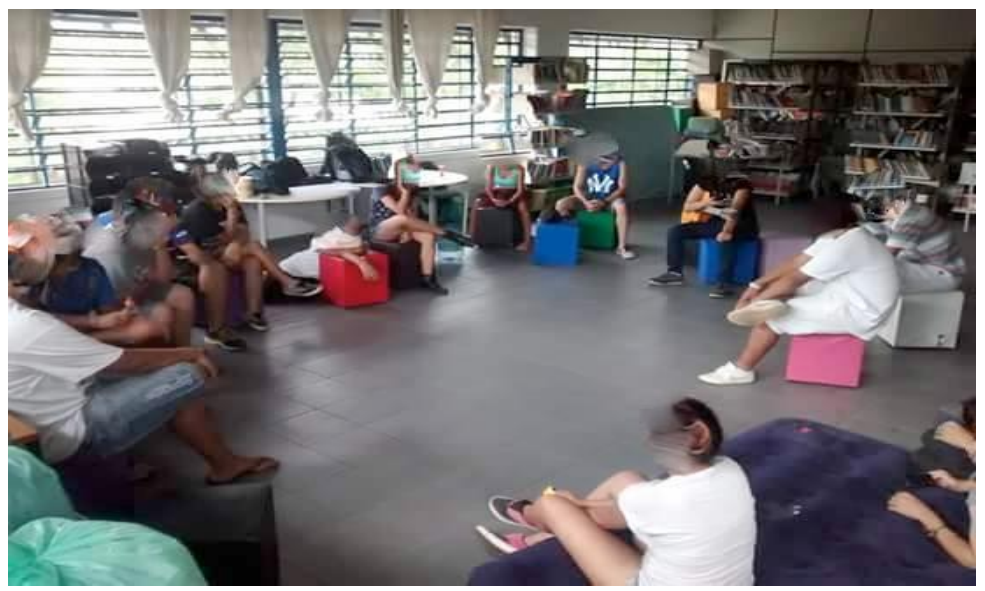

FIGURA 3 - Biblioteca onde os/as jovens faziam reuniões

Fonte: Diário de campo

A palestrante passou a descrever diversos processos atuais de colonialidade. Por um lado, sua fala corroborou com o que Miranda (2016) destaca quando chama a atenção sobre como os processos de colonização estão presentes nas diversas searas da sociedade, tais como a economia, o conhecimento, os livros didáticos e os currículos escolares. Podese, de certo modo, afirmar que estes estão mergulhados no interior de processos mais amplos, profundos e complexos, como o saber e o poder (GOMES, 2012). Trata-se, portanto, de uma perspectiva responsável pela construção de um discurso subalterno que está inserido, de diversos modos, na subjetividade dos povos não ocidentais, também conhecida como "colonialidade do poder" (QUIJANO, 2005).

Por outro lado, o posicionamento da palestrante enfatizou e indicou o contexto das ocupações como um processo possível de descolonização das escolas, o qual, segundo Gomes (2012), tem ocorrido gradualmente ao longo do tempo, na medida em que os/as excluídos/as passam a organizar-se tanto individual quanto coletivamente, em busca de mudanças paradigmáticas, principalmente naquilo que diz respeito às políticas de identidade.

Numa perspectiva de descolonização dos currículos e na compreensão das rupturas epistemológicas e culturais trazidas pela questão racial na educação brasileira, concordo com o fato de que esse olhar é um alerta importante. A compreensão das formas por meio das quais a cultura negra, as questões de gênero, a juventude, as lutas dos movimentos sociais e dos grupos populares são marginalizadas, tratadas de maneira desconectada com a vida social mais ampla e até mesmo discriminadas no cotidiano da escola e nos currículos pode ser

(C) ETD-Educação Temática Digital Campinas, SP v.19 $\quad$ n.1 $\quad$ p. 26-48 jan./mar. 2017 
considerado um avanço e uma ruptura epistemológica no campo educacional (GOMES, 2012, p. 104).

O contexto da palestra provocou a manifestação de alguns dos estudantes. Um deles falou sobre as grades da escola como forma de opressão e sobre a relação entre os/as professores/as e os/as jovens, apontando o fato de que é comum os/as professores/as não deixá-los/las ir ao banheiro ou beber água e ressaltou que, em determinados momentos, sentem-se tratados/as como animais. O relato desse jovem chama a atenção e nesse sentido é importante mencionar que, segundo Santos (2005), a desumanização é uma das formas primárias do racismo brasileiro. Ao tratar os/as estudantes como animais, o currículo escolar reforça a necessidade de sua descolonização, ou seja, como assinalou Gomes (2012), é preciso que haja uma mudança de paradigma que seja capaz de expor os conflitos, os confrontos, as relações de poder e promover um profundo processo de reflexão e ações cotidianas voltadas à justiça social.

Ao complementar o comentário do jovem, uma professora disse que o prédio tem, aproximadamente, dez anos e as grades começaram a ser colocadas há cerca de dois anos. O motivo seria o fato de os/as jovens tentarem entrar ou sair da escola sem autorização. Outro jovem chamou a atenção para o fato de que era possível encontrar estudantes nos corredores durante o período de aula e argumentou: "se ele não entra na aula é porque a aula não o motiva, não havia identificação".

Similar ao que foi observado em duas outras pesquisas (ZAN e POSSATO, 2014) é possível concluir que os discursos de dominação e poder estão expressos nas grades das escolas. Nesse sentido, cabe afirmar que a escola para a população pobre de nosso país tem cumprido uma função fundamental de disciplinamento e controle, se contrapondo a qualquer possibilidade de contribuição para a construção da autonomia e liberdade dos sujeitos (ZAN e POSSATO, 2014).

Ao mencionar as grades da escola como uma forma de colonização do currículo escolar, a professora e o jovem estudante da Escola 2 indicam uma contradição nas ações e a possibilidade de subverter essa lógica disciplinadora e controladora. Enquanto as grades são colocadas para que os/as estudantes não entrem ou saiam da escola sem autorização, muitos dos/as que entram não se sentem à vontade para permanecer na sala durante as aulas. Esses últimos se recusam a sair da escola, formam grupos de sociabilidade e se apropriam dos espaços escolares, como os corredores, e a eles dão novos usos e sentidos. Tal fato se coaduna com o estudo de Dayrell (1996) ao mostrar que os/as jovens

(C) ETD-Educação Temática Digital Campinas, SP v.19 $\quad$ n.1 $\quad$ p. 26-48 jan./mar. 2017 
ressignificam os espaços escolares, de modo a legitimar as múltiplas culturas juvenis inseridas nesse contexto.

Ao falar sobre o constante retrocesso segundo o qual a escola estava passando, principalmente no que diz respeito aos direitos dos/as estudantes, um dos jovens comentou que a vice-diretora havia dito que queria acabar com o grêmio, pois a agremiação não fazia parte do projeto da escola naquele ano. Segundo o jovem, a equipe que formava o grêmio insistiu por sua continuidade, mas a direção o boicotou. De certo modo, trata-se de um processo de colonização dos espaços de decisão, ou seja, dos espaços segundo os quais o exercício do poder é percebido como mais legítimo.

Espaços como o grêmio escolar podem ser entendidos como possibilidades de construção de outros sentidos. Como afirma Carrano (2012), um dos motivos pelos quais a falta de diálogo está presente no contexto escolar passa pela ausência de políticas adequadas, causando o que ele chama de "incomunicabilidade entre os sujeitos escolares". No entanto, segundo o autor, são as práticas produtoras de sentido aquelas que proporcionam a participação efetiva dos/as jovens nos variados espaços escolares, como aqueles onde é necessário tomar decisões.

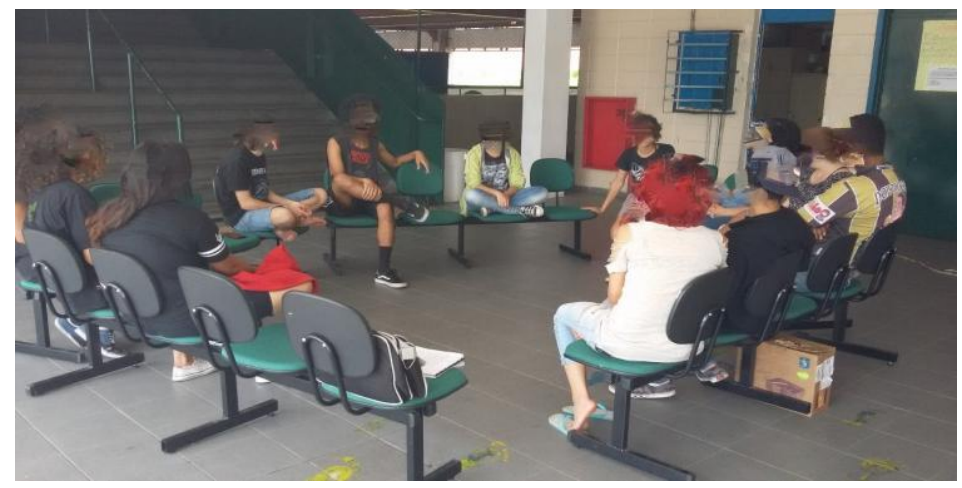

FIGURA 4 - Palestra sobre Pós-colonialismo Fonte: Diário de campo

No dia 11 de dezembro, ao chegar à escola, encontrei um aluno colocando um cartaz na lateral do prédio. Após fotografá-lo, me dirigi até o portão do estacionamento, que era o local por onde os/as jovens entravam e saiam da escola. No mesmo dia, estava prevista a palestra "Educação na atualidade" e para fazê-la a professora passou um vídeo chamado "A

(C) ETD-Educação Temática Digital Campinas, SP v.19 $\quad$ n.1 $\quad$ p. 26-48 jan./mar. 2017 
escola é um saco" ${ }^{\prime 8}$ e dialogou sobre o direto de acesso à universidade pública. Com estranheza foi possível observar que havia poucos/as jovens na palestra. Ao indagar sobre o motivo, uma estudante respondeu que eles/as ficavam se revezando na ocupação e que naquele horário muitos/as tinham ido até suas casas e retornariam mais tarde. Dessa forma, não deixavam a escola vazia.

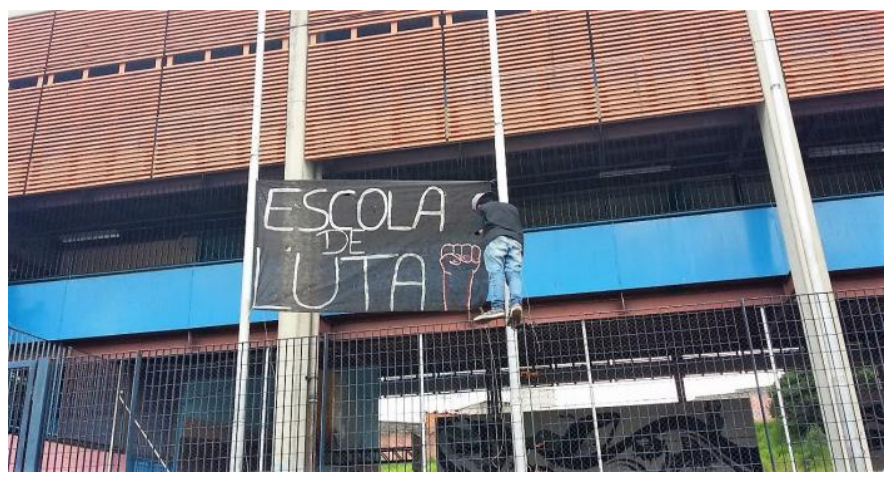

FIGURA 5 - Cartaz na lateral externa da escola

Fonte: Diário de campo

Desde a primeira palestra, dois aspectos foram recorrentes e chamaram a atenção: sempre apareciam nas falas dos/as estudantes, a arquitetura da escola e o relato das aulas marcadas pela mera reprodução de textos no quadro para serem copiados pelos/as estudantes. Uma jovem falou que eles/as ficam desestimulados pelo fato de que a maioria das aulas é apenas para copiar lição e relacionou a tarefa com o trabalho mecânico de uma fábrica, apontando que a tarefa que Ihes cabia, enquanto alunos/as, era apenas a repetição de um movimento.

Um estudante comparou o ensino daquela escola com o ensino da escola de dança urbana, da qual ele participava. Ele disse que as duas escolas trabalham de forma mecânica, mas na dança eles podem criar, ao mesmo tempo em que o/a professor/a explica a construção histórica do movimento. Ao questionar o paradigma da escola atual, ele disse que os/as professores/as "precisam ser mais educadores/as do que professores/as". Em seguida, uma das professoras da escola, que estava apoiando a ocupação, realizou uma crítica aos conteúdos do currículo, disse que eles se repetem de modo tradicional e apontou que a história da África, por exemplo, não é abordada durante as aulas.

\footnotetext{
${ }^{8}$ Trata-se de uma animação produzida por Gustavo Horn e tem como objetivo promover uma reflexão sobre o papel da escola na sociedade. GUSHORN Produções. YouTube, publicado em: 1 mar. 2013. Disponível em: <https://www.youtube.com/watch?v=qrXk_U0aORo>. Acesso em: 23 fev. 2017.
}

(C) ETD-Educação Temática Digital Campinas, SP v.19 $\quad$ n.1 $\quad$ p. 26-48 jan./mar. 2017 
Os questionamentos destes/as jovens remetem a uma escola precária, mecanizada e colonizada nas relações estabelecidas, em sua arquitetura e na relação com os saberes. A ocupação realizada pelos/as jovens estudantes desta escola é indicativo de que, para além de questionar a reorganização anunciada pela Secretaria de Educação do Estado de São Paulo, eles/as estão reivindicando a descolonização de um espaço e de uma relação entre os/as estudantes e os/as atores/as da escola. Nesse espaço, nem mesmo a arquitetura tem proporcionado um diálogo e uma relação democrática em que todos/as possam intervir e contribuir para sua transformação.

\section{A OCUPAÇÃO COMO ESPAÇO DE CONFRONTOS E RESISTÊNCIAS}

Ao dirigir-se até a escola para verificar como estava a ocupação, percebi que havia um homem no portão que chamava por alguém no interior da escola. Ao se aproximar, cumprimentou-o e um jovem estudante nos atendeu e nos convidou para entrar. Foi então que precisei retornar para trancar o carro antes, ao que o homem prontamente reagiu: "não precisa, o meu também tá aberto, aqui ninguém mexe nas nossas coisas, pode ficar de boa, se alguém mexer nós vai atrás e recupera".

Após o início da conversa, foi possível perceber que se tratava de um representante do "morro", como os/as jovens diziam. Ele queria saber o que estava ocorrendo na escola, disse que a comunidade comentou que a escola estava privando as pessoas de fazerem matrícula e isso poderia ser um problema para o morro. Então os dois garotos que acompanhavam o homem explicaram que a situação não era essa. Disseram que eles conversaram com a direção da escola, que se recusou a fazer as matrículas enquanto ela estivesse ocupada. Fato que foi presenciado por mim no dia em que houve a conversa entre os/as professores/as, a conselheira tutelar e a direção, em uma situação tensa.

Então, o representante do morro se apresentou como integrante de uma facção criminosa e disse que a única coisa que ele pedia era que ninguém mexesse em nada na escola e que não levassem nada para casa, pois a escola era da comunidade. Disse que o morro e a comunidade apoiam a ocupação porque eles sabem que o movimento é para a melhoria e será bom tanto para seus/suas filhos/as como para os/as filhos/as da comunidade.

(C) ETD-Educação Temática Digital Campinas, SP v.19 $\quad$ n.1 $\quad$ p. 26-48 jan./mar. 2017 
A conversa continuou e foi possível perceber que ele queria mais informações sobre o que estava ocorrendo dentro da escola. Nesse momento, passei, então, a ajudar os/as jovens na sua argumentação. Falaram sobre os espaços da escola que devem ser disponibilizados para a comunidade e não são, bem como sobre as verbas que chegaram à escola e não se sabia como haviam sido empregadas, pois a prestação de contas por parte da direção não aconteceu. Uma professora também começou a argumentar, falou sobre a necessidade de retirar o mato e perguntou quem poderia contribuir disponibilizando o trabalho pessoal e/ou material. O rapaz quis conhecer as pessoas que estavam ali e, então, me apresentei como professor de uma escola vizinha (a escola da Prefeitura de São Paulo na qual estou vinculado, embora afastado em razão do doutorado), e falei sobre a pesquisa em andamento naquela instituição escolar. Nesse momento, o morador perguntou sobre quais seriam os benefícios de uma pesquisa como essa para a escola.

Foi explicado que a escola terá acesso aos resultados da pesquisa e que, de certo modo, esse trabalho poderá colaborar para que a equipe da escola rediscuta sua organização com o objetivo de melhorar a relação entre os/as funcionários/as e os/as estudantes. O morador pareceu satisfeito e disse que era para os/as jovens apoiarem esse trabalho porque se tratava de mais um professor que está junto à luta deles/as. Foi um momento de alívio. O rapaz se despediu do grupo e foi embora. Os/as jovens me agradeceram pela ajuda e então pude entrar na escola e fazer algumas fotografias.

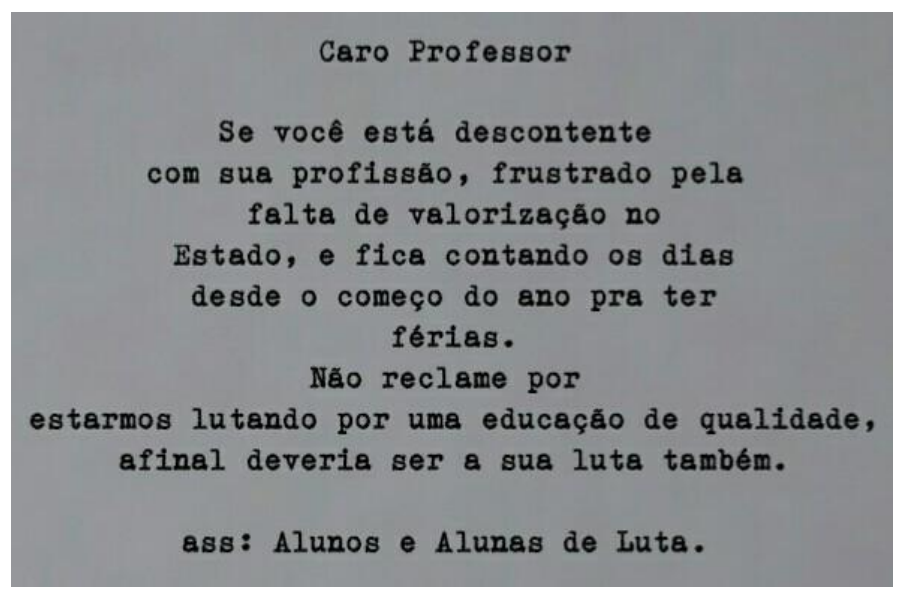

FIGURA 6 - Recado dos/as estudantes

Fonte: Diário de campo

(C) ETD-Educação Temática Digital Campinas, SP $\quad$ v.19 $\quad$ n.1 $\quad$ p. 26-48 jan./mar. 2017 


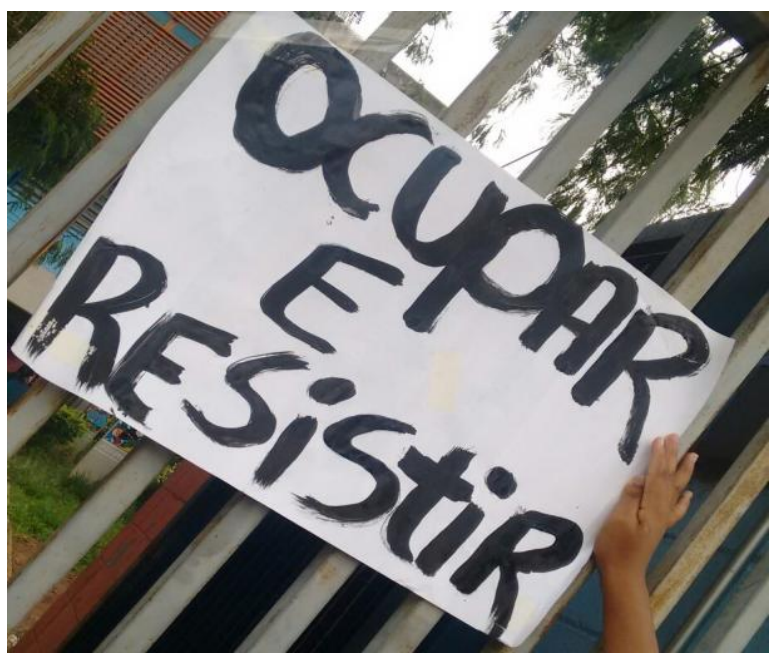

FIGURA 7 - Ocupar e resistir

Fonte: Diário de campo

No dia 15 de dezembro, os/as estudantes me enviaram uma mensagem pelo WhatsApp para avisar sobre uma reunião emergencial que ocorreria às $20 \mathrm{~h}$ com o objetivo de conversar sobre os encaminhamentos da ocupação. Chegando à escola, subi até a sala indicada no convite. Os estudantes formaram um semicírculo e três deles/as sentaram-se em uma mesa de frente para o grupo. Era possível notar que eles/as tinham um livro para registrar as reuniões. A mesa era composta por duas meninas e um menino. Essa situação reforça o que vinha sendo registrado desde o início da ocupação: havia uma participação intensa de meninas nos processos de organização e decisão no interior da ocupação.

Na reunião, havia oito meninas, cinco meninos e uma professora, sem contar os/as que foram chegando durante a reunião. Eles/as eram extremamente organizados/as, a fala era por inscrição, cada pessoa tinha dois minutos para falar e este tempo era cronometrado pelos membros da mesa. Havia uma pauta que previa o tempo de 15 minutos para informes, 15 minutos para assuntos específicos, 15 minutos para divisão de responsabilidades e 40 minutos para apresentação das reivindicações.

(C) ETD-Educação Temática Digital Campinas, SP v.19 $\quad$ n.1 $\quad$ p. 26-48 jan./mar. 2017 
De certo modo, é possível afirmar que além da escola investigada, o formato de assembleia foi aderido por todo o movimento de ocupação em São Paulo como forma de manter uma organização democrática e teve como inspiração o manual de ocupação "Como ocupar um colégio?", documento produzido pela Frente de Estudiantes Libertários para descrever a experiência argentina, inspirada pela luta dos/as estudantes chilenos/as (JANUÁRIO et al., 2016). No entanto, o manual não foi a única fonte de inspiração dos/as estudantes da Escola 2, foi possível perceber que houve um diálogo bastante intenso com ocupantes de outras escolas. Eles/as interagiam tanto pessoalmente, por meio de visitas agendadas, quanto por mensagem no celular. Desse modo, eles/as contribuíram com o relato sobre como eles se organizaram no interior de suas instituições.

$\mathrm{Na}$ assembleia, iniciaram com informes, comentaram sobre escolas que foram desocupadas e algumas que estavam programadas para a desocupação. Receberam a informação de que o governador mandaria a polícia invadir as escolas que permanecessem ocupadas durante o período do Natal, para realizar uma desocupação em massa.

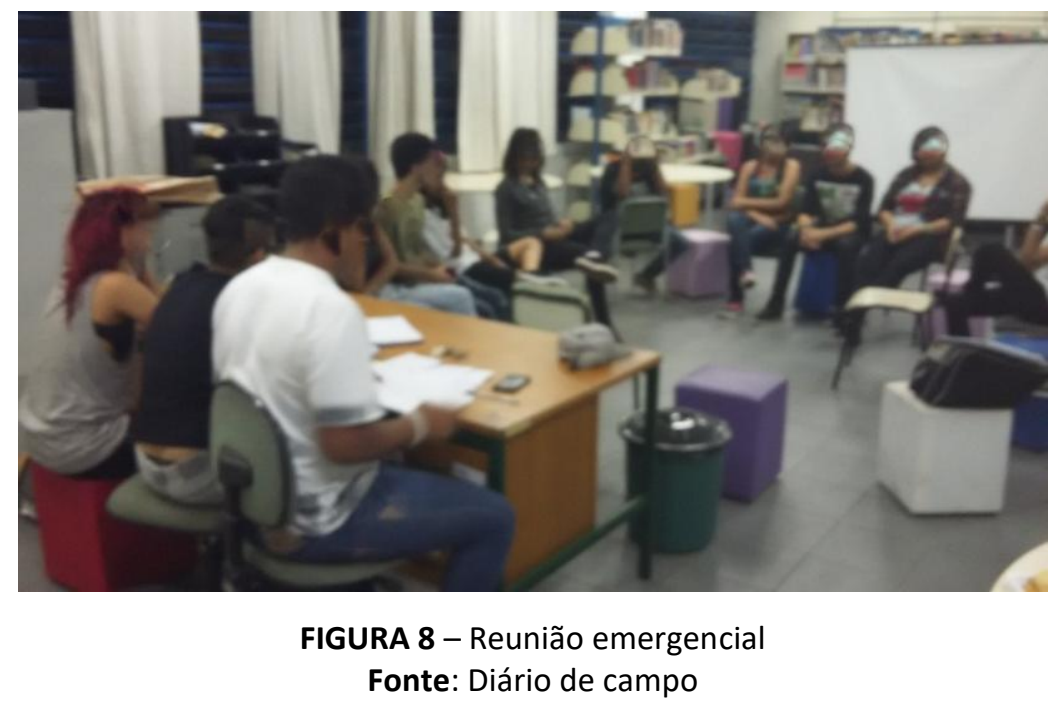

Nesse momento, informaram da suspeita de que os celulares estivessem grampeados, por isso não deveriam passar informações importantes por mensagens ou ligações. Comentaram sobre algumas cartas que estavam chegando para assinatura deles/as, com a justificativa de ser essa uma forma de comprovar o recebimento de doações de alimentos. Um estudante disse que, na verdade, na carta constava que a pessoa concordaria em sair da escola e abrir mão da ocupação. Assim, ele pediu, como prevenção, que ninguém assinasse qualquer tipo de documento que chegasse à ocupação.

(C) ETD-Educação Temática Digital Campinas, SP v.19 $\quad$ n.1 $\quad$ p. 26-48 jan./mar. 2017 
Comentaram que a equipe de gestão da escola trabalharia na escola no dia seguinte, após acordo realizado. Um dos meninos disse que é preciso tomar cuidado ao transitar no entorno da escola, pois tinham notícia de que havia pessoas seguindo os jovens, principalmente viaturas da polícia, que ficavam rondando a escola o tempo todo. Um deles ressaltou que foi seguido, abordado pela Força Tática da Polícia Militar do Estado de São Paulo e questionado se ele era ocupante; o rapaz negou.

Os/as jovens estavam pensando no momento de desocupar a escola, estavam com muito medo, ressaltaram que era preciso desocupar juntamente com todas as escolas que ainda estavam ocupadas, para não ficarem como foco e não sofrerem violência da polícia. Em seguida, definiram responsabilidades e de quem seriam as tarefas de limpeza e segurança ao longo da semana.

Quanto às reivindicações, eles/as conversaram sobre o que deveriam solicitar em diálogo com a direção da escola, pois estava prevista uma reunião para conversar diretamente com a diretora sobre as reivindicações da ocupação. Sendo assim, definiram a seguinte lista:

\section{Lista de reivindicações ${ }^{9}$ :}

- Aulas extracurriculares (intervalo e finais de semana);

- Dedetização na escola;

- Estrutura física para pessoas com deficiência física;

- Grêmio;

- Melhoria das aulas (mais diálogo com professores/as);

- Pista de skate no lugar do matagal e bancos de concreto no lugar do barranco (segundo uma professora, esta estrutura está prevista na planta da escola);

- Prestação de contas dos gastos mensais liberada para os/as alunos/as (conselho de escola);

\footnotetext{
${ }^{9}$ É importante ressaltar que para uma maior organização, a lista foi escrita em ordem alfabética.
}

(C) ETD-Educação Temática Digital Campinas, SP v.19 $\quad$ n.1 $\quad$ p. 26-48 jan./mar. 2017 
- Reformulação dos horários de intervalo;

- Remanejamento de professores/as;

- Troca de alguns/mas funcionários (diretora, inspetora, professores/as);

- Utilização da biblioteca, com profissional para atendimento;

- Ventiladores.

Durante a reunião, era comum perceber conversas paralelas, brincadeiras que não eram bem-vistas pelo restante dos/as jovens e até mesmo discussões sobre algum outro tema, que não tinham relação com o foco central da reunião; atitudes como essas eram chamadas por eles/as de "caso de família". Tal nomenclatura foi ressignificada e inspirada em um programa do SBT, que com o mesmo nome, tinha como objetivo a promoção de um debate entre pessoas que passavam por problemas familiares e a apresentadora do programa. Trazendo, muitas vezes, dramas individuais e pessoais para um tratamento espetacularizado na televisão. Nos momentos em que as discussões iniciavam, muitos/as deles/as diziam: "sem casos de família, perde o foco da reunião". Durante a reunião também informou-se que uma pesquisa estava em andamento na escola e eu aproveitei para anunciar meu desejo de realizar um encontro de grupo para poder conversar com os/as estudantes, o que foi muito bem recebido e todos/as aceitaram participar.

No dia 16 de dezembro, ao chegar à escola para a realização da roda de conversa com os/as estudantes notei que os funcionários da direção estavam na instituição trabalhando. Alguns jovens controlavam a entrada e saída de todos. Aquela cena, apesar de estar acompanhando a ocupação desde o seu início, chamou a minha atenção, pois foi a primeira vez que foi presenciei uma cena representativa da desconstrução das relações de poder anteriormente estabelecidas naquela escola, onde as interações entre adultos/as e jovens estavam assentadas em princípios hierarquizantes. Enquanto eu estava na sala de reuniões fotografando o quadro de atividades, o vice-diretor apareceu e, com aparência irritada, pediu para os/a jovens abrirem a porta para ele ir embora, pois eram eles/as que estavam coma chave e o controle de entrada e saída da escola.

Após a realização da roda de conversa, por volta das $23 \mathrm{~h}$, quando me organizava para ir embora, notei que começaram a chamar no portão. Dois meninos desceram e, após

(C) ETD-Educação Temática Digital Campinas, SP $\quad$ v.19 $\quad$ n.1 $\quad$ p. 26-48 jan./mar. 2017 
cerca de cinco minutos, chegou a informação de que havia homens armados do lado de fora e que eles iam entrar para atirar em todos/as que estavam na ocupação. O semblante dos/as jovens mudou totalmente, o medo estava estampado no rosto deles/as que, desesperados, passaram a organizar tudo para que o espaço não parecesse bagunçado. Um dos meninos subiu e disse que eles queriam que a professora descesse para conversar. A professora desceu junto de um metroviário que apoiava a ocupação; também desci. Nós éramos os/as únicos/as maiores de 18 anos no grupo.

Durante o tempo em que a professora passou conversando com os rapazes, coube a mim o papel de tentar acalmar os/as jovens, o que foi muito difícil, diante da tensão que se espalhou naquele ambiente. Alguns estudantes foram para o outro lado da escola e constataram que, de fato, havia homens cercando a escola. Enquanto isso, outros/as meninos/as traçavam uma estratégia de fuga, caso os rapazes entrassem atirando na escola, mas devido ao fato de a escola possuir muros altos e cercas em todos os lugares, além do cerco feito pelos homens, a estratégia para escapar não parecia muito viável.

Após aproximadamente cinquenta minutos de conversa, um dos rapazes da comunidade subiu com os meninos, entrou na biblioteca, espaço em que o grupo estava e conversou com as/os estudantes. Disse que recebeu uma ordem para apagar as luzes e atirar em todos/as, porque foram reclamar para eles dizendo que "invadiram" a escola para fazer bagunça, usar drogas, beber e depredá-la. No entanto, segundo ele, os meninos disseram que havia professores/as no interior da escola e ele resolveu entrar e conversar. A partir de sua entrada, disse que viu que tudo estava organizado, não havia droga e nem bebida, que havia professores/as e disse: "se há professor é porque não tem bagunça".

A perspectiva oriunda da fala do rapaz da comunidade está relacionada ao fato de que o/a professor/a é um modelo inquestionável de autoridade no interior da escola. Ao lado disso, percebe-se que estamos longe da construção de um olhar em que o/a jovem pode ser tido como um sujeito ativo no processo nas práticas escolares, pois como afirma o rapaz, se não houvesse professor na escola, o risco de bagunça seria muito maior, em contrapartida, como havia professor no interior da escola, este risco seria nulo.

O homem orientou os meninos a divulgar a ocupação, chamar a comunidade para fazer as atividades da escola e mostrar que o que eles estavam fazendo era bom para todos/as. Ele disse que entendeu e que a filha dele ia estudar lá, comentou que eles/as deveriam procurar outro modo de protestar, como parar uma avenida, por exemplo, pois

(C) ETD-Educação Temática Digital Campinas, SP $\quad$ v.19 $\quad$ n.1 $\quad$ p. 26-48 jan./mar. 2017 
mexer com política é mexer com o morro e se atraíssem polícia para lá seria complicado porque tem muita gente que deve muitos anos de cadeia.

Depois de cerca de 25 minutos conversando com os meninos, o rapaz desceu. Outro rapaz da comunidade estava conversando com outro estudante. Eles também subiram e o estudante mostrou a organização da escola. Ficaram muito tempo conversando e foram embora. Os estudantes comentaram depois ter percebido que os visitantes estavam com os olhos muito vermelhos, que deveriam estar drogados.

A situação relatada é reveladora no que diz respeito ao modo como as relações entre escola e comunidade são tecidas naquela localidade. $O$ garoto que conversou com os rapazes parecia muito seguro durante a conversa, utilizava a mesma linguagem, gírias e expressões que os homens, o que mostrou um senso de pertencimento daquele lugar. Também ficou muito claro que naquele espaço seria necessário o cumprimento de regras previamente estabelecidas, mas que não tinham relação alguma com o Estado, e sim com um conjunto de regras construídas entre as pessoas daquele lugar, regras estas que transcendiam o poder de organização do Estado, mas que eram necessárias para o convívio e a ordem daquele local.

Após esse episódio, os/as jovens/as mostraram a pauta da reunião e explicitaram quais reivindicações deveriam apresentar para a diretora, que iria à escola no dia seguinte. Finalmente, por volta da $1 \mathrm{~h} 30 \mathrm{~min}$, todos haviam deixado a escola e também pude ir embora.

No dia 17 de dezembro, ao chegar à escola, percebi que os/as jovens a haviam desocupado e a direção tinha reassumido seu posto de trabalho. No dia seguinte, chegou a informação de que haveria uma reunião na casa de um dos jovens ocupantes. Além dos/as jovens, compareceriam um professor, duas professoras e uma estudante de Letras da USP que participava de um movimento estudantil. Eles/as conversaram sobre a experiência da ocupação, sua importância e as principais dificuldades pelas quais passaram. Também discutiram sobre os próximos passos, como a participação em manifestações, por exemplo. Disseram que no dia da desocupação, eles/as saíram da escola com um documento assinado pela diretora comprometendo-se a fazer as mudanças solicitadas.

(C) ETD-Educação Temática Digital Campinas, SP $\quad$ v.19 $\quad$ n.1 $\quad$ p. 26-48 jan./mar. 2017 


\section{CONSIDERAÇÕES FINAIS}

A experiência no interior da ocupação mostrou que o ambiente hostil observado no cotidiano da escola ao longo do ano letivo foi modificado durante o período de ocupação. Os/as estudantes, que são nomeados/as como os/as desordeiros/as e desinteressados/as, se mostraram organizados/as e com grande disposição colaborativa para preservar e defender a instituição escolar.

O processo de ocupação proporcionou uma difícil condição para os/as professores/as e a gestão, que foram questionados/as em sua autoridade. Tal questionamento pode ser considerado como parte de um processo de descolonização do ambiente escolar, pois se trata de uma forma de transformação efetiva das relações autoritárias cotidianamente estabelecidas no interior da escola, e constatadas ao longo de pesquisa realizada naquela escola.

Sentindo-se ultrajados, gestão escolar e alguns/mas docentes colocaram-se em oposição ao movimento estudantil, sem seque abrir-se para o diálogo e a compreensão das razões dos/as estudantes. De certo modo, é possível afirmar que os/as representantes da instituição se colocaram como uma ameaça ao movimento estudantil, da mesma forma como as lideranças do crime organizado presente naquela comunidade.

Foi, no entanto, graças ao apoio de algumas docentes, alguns colaboradores/as externos, como a advogada que se dispôs a atuar em defesa dos/as jovens, e a possibilidade de convencimento da comunidade, que os/as estudantes tiveram o respaldo e a possibilidade de manterem-se durante os intensos 14 dias de ocupação.

É notável o papel de destaque e participação ativa que as meninas adquiriram nesse movimento. Durante o tempo em que estive na escola, desenvolvendo a pesquisa de campo para a tese de doutorado, não havia sido observado outro momento de tamanho destaque nas relações estabelecidas entre as jovens meninas e os diversos processos educativos. No entanto, na ocupação, meninas negras, lésbicas e bissexuais assumiram importantes funções nos processos de organização e de tomada decisão, fato representativo de como a ocupação da escola produziu outro ambiente de aprendizagem, mais participativo e democrático. ${ }^{i}$

(C) ETD-Educação Temática Digital Campinas, SP v.19 $\quad$ n.1 $\quad$ p. 26-48 jan./mar. 2017 


\section{REFERÊNCIAS}

CAMPOS, Antônia Malta; MEDEIROS, Jonas; RIBEIRO, Márcio Moretto. Escolas de luta. São Paulo: Veneta, 2016.

CARRANO, Paulo. Identidades culturais juvenis e escolas: arenas de conflitos e possibilidades. In: MOREIRA, Antônio Flávio; CANDAU, Vera Maria. Multiculturalismo: diferenças culturais e práticas pedagógicas. Petrópolis: Vozes, 2013.

DAYRELL, Juarez. A escola como espaço sócio-cultural. In: DAYRELL, Juarez (Org.). Múltiplos olhares sobre educação e cultura. Belo Horizonte: Ed. UFMG, 1996.

GOMES, Nilma Lino. Corpo e cabelo como ícones de construção da beleza e da identidade negra nos salões étnicos de Belo Horizonte. São Paulo, 2002. Tese (Doutorado). Faculdade de Filosofia, Letras e Ciências Humanas da Universidade de São Paulo.

GOMES, Nilma Lino. Relações étnico-raciais, educação e descolonização dos currículos. Currículo sem fronteiras, v.12, n.1, pp. 98-109, jan./abr. 2012.

HOOKS, Bell. Alisando o nosso cabelo. Revista Gazeta de Cuba - Unión de Escritores y Artista de Cuba, jan./fev. 2005.

JANUÁRIO, Adriano et al. As ocupações de escolas em São Paulo (2015): autoritarismo burocrático, participação democrática e novas formas de luta social. Revista Fevereiro, n.9. abr. 2016.

KELLNER, Douglas. Lendo imagens criticamente: em direção a uma pedagogia pós-moderna, in SILVA, Tomaz Tadeu (Org.). Alienígenas na sala de aula: uma introdução aos estudos culturais em educação. Petrópolis: Vozes, 1995.

LÜDKE, Menga; ANDRÉ, Marli E. D. A. Pesquisa em educação: abordagens qualitativas. São Paulo: Ed. Pedagógica e Universitária, 1986.

MIRANDA, Cláudia. Sobre outras pedagogias e discursos insurgentes. In: CORSINO, Luciano Nascimento; CONCEIÇÃO, Willian Lazaretti da. (Orgs.). Educação física escolar e relações étnico-raciais: subsídios para a implementação das Leis 10.635/03 e 11.645/08. Curitiba: CRV, 2015.

OLIVEIRA, Amurabi. Etnografia e pesquisa educacional: por uma descrição densa da educação. Educação Unisinos, v. 17, n. 3, pp. 271-280, set./dez. 2013.

(C) ETD-Educação Temática Digital Campinas, SP v.19 $\quad$ n.1 $\quad$ p. 26-48 jan./mar. 2017 
QUIJANO, Anibal. Colonialidad del poder, eurocentrismo y América Latina. In: LANDER, Edgardo (Org.) La colonialidad del saber: eurocentrismo y ciencias sociales. Perspectivas latino-americanas. Buenos Aires: CLACSO/UNESCO, 2000.

SANTOS, Sales Augusto dos. Introdução. In: SANTOS, Sales Augusto dos. Ações afirmativas e combate ao racismo nas Américas. Brasília: Ministério da Educação, Secretaria de Educação Continuada, Alfabetização e Diversidade, 2005. 400 p. (Coleção Educação para Todos).

TURA, Maria de Lourdes Rangel. A observação do cotidiano escolar. In: ZAGO, Nadir; CARVALHO, Marilia Pinto de; VILELA, Rita Amélia Teixeira. (Org.). Itinerários de pesquisa: perspectivas qualitativas em Sociologia da Educação. Rio de Janeiro: DP\&A, 2003.

VALVERDE, Danielle Oliveira; STOCCO, Lauro. Notas para a interpretação das desigualdades raciais na educação. In: BONETTI, Alinne de Lima; ABREU, Maria Aparecida A. (Org.). Faces da desigualdade de gênero e raça no Brasil. Brasília: Ipea, 2011.

VIANNA, Heraldo Marelim. Pesquisa em educação: a observação. Brasília: Plano, 2003.

ZAN, Dirce; POSSATO, Beatris Cristina. Espaços Cerrados: as marcas da violência e do controle na arquitetura das escolas. Revista e-Curriculum, São Paulo, v. 12, n. 3, out./dez. 2014.

\section{Agradecimentos}

Ao apoio financeiro da Coordenação de Aperfeiçoamento de Pessoal de Nível Superior CAPES e ao Laboratório de Estudos sobre Violência, Cultura e Juventude - VIOLAR/UNICAMP

\footnotetext{
' Revisão gramatical do texto por: Mônica Rodrigues dos Santos
} 